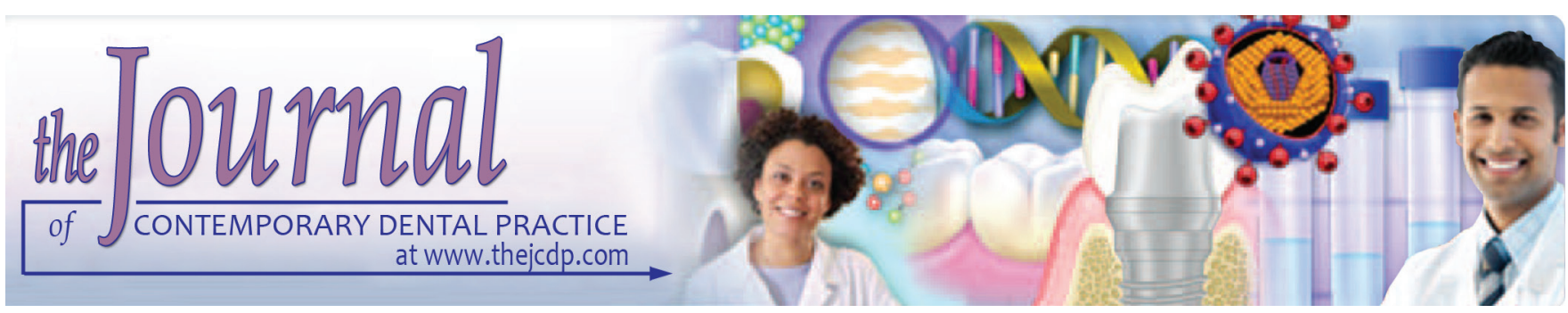

\title{
Reliability of Orthopantomography and Cone-beam Computed Tomography in Presurgical Implant Planning: A Clinical Study
}

\author{
1Jasjit Sahota, ${ }^{2}$ Aditya Bhatia, ${ }^{3}$ Megha Gupta, ${ }^{4}$ Vishal Singh, ${ }^{5}$ Juhi Soni, ${ }^{6}$ Richa Soni
}

\begin{abstract}
Background: Preoperative diagnosis and treatment planning are fundamental requirements to ensure success rate of implant. Cone-beam computed tomography (CBCT) provides all three dimensions and has been proved as a tool for radiology, especially in the success of implant. This study was conducted to evaluate the reliability of orthopantomography (OPG) and CBCT in presurgical implant planning.
\end{abstract}

Materials and methods: The study was conducted on 110 partially or completely edentulous adult patients (male 50 and female 60). Patient information regarding name, age, gender, and so forth was recorded. Thorough clinical examination was done to locate the edentulous site for the placement of implant. All patients were subjected to OPG and CBCT.

The OPG was taken with digital panoramic unit (Planmeca) operating at $120 \mathrm{kVp}, 2 \mathrm{~mA}$, and exposure time of 17 seconds. The CBCT was taken using NewTom machine with field of view $11 \times 8 \mathrm{~cm}$ and resolution of $0.3 \times 0.3 \times 0.3 \mathrm{~mm}$ operating at $120 \mathrm{kVp}$ at $5 \mathrm{~mA}$. NNT software with slice thickness of $0.1 \mathrm{~mm}$ was used in this study.

Measurement of bone height and distance from anatomical structures was done on OPG, whereas bone height and bone width were measured on $\mathrm{CBCT}$ scan in all three planes, such

\footnotetext{
${ }^{1}$ Department of Periodontics, Maharaja Ganga Singh Dental College \& Research Centre, Sri Ganganagar, Rajasthan, India

${ }^{2}$ Department of Prosthodontics, Shree Bankey Bihari Dental College and Research Centre, Ghaziabad, Uttar Pradesh, India

${ }^{3}$ Department of Oral and Maxillofacial Surgery, SGT Dental College Hospital \& Research Institute, Gurgaon, Haryana, India

${ }^{4}$ Department of Prosthodontics, Vananchal Dental College Garhwa, Jharkhand, India

${ }^{5,6}$ Department of Oral Pathology, Shree Bankey Bihari Dental College and Research Centre, Ghaziabad, Uttar Pradesh, India

Corresponding Author: Jasjit Sahota, Department of Periodontics, Maharaja Ganga Singh Dental College \& Research Centre, Sri Ganganagar, Rajasthan, India, Phone: +919501544877, e-mail: drjasjitsahota@gmail.com
}

as coronal plane, sagittal plane, and axial plane. The measurement was done by two experienced observers.

Results: The present study comprised 110 patients (male 50 and female 60). About 102 (16.7\%) implants were placed in anterior region, and $508(83.3 \%)$ implants were placed in posterior region. Implant site was incisor region (55), canine (30), premolar (250), and molar (275). The difference was significant $(p<0.01)$. Variations are usually observed in presurgical planning with CBCT and OPG. The length and width of implant remained unchanged in 90 and $85 \%$ of the cases respectively. In $8 \%$ of cases, OPG revealed more length of implant than $\mathrm{CBCT}$, whereas only in $2 \%$ cases CBCT revealed more length of implant than OPG. The difference was significant $(p<0.05)$. When we compared the diameter, OPG revealed more diameter in $10 \%$ of cases, whereas CBCT only revealed $5 \%$ of cases. The difference was significant $(p<0.05)$. Observer found CBCT as effective in $95 \%$ of cases and ineffective in only $5 \%$ of cases, whereas OPG was effective in $78 \%$ of cases and ineffective in $22 \%$ of cases. The different was significant $(p<0.05)$.

Conclusion: The CBCT being three-dimensional provides detailed information that two-dimensional radiographs cannot offer, which aids in precision to further improve the entire implant process.

Clinical significance: In recent times, implant has become the treatment of choice for edentulous patients. The CBCT has increased the success rate of implant due to its high resolution, ability to demonstrate anatomical structures more effectively than other radiographic diagnostic tools.

Keywords: Bone height, Cone-beam computed tomography, Orthopantomography.

How to cite this article: Sahota J, Bhatia A, Gupta M, Singh V, Soni J, Soni R. Reliability of Orthopantomography and Conebeam Computed Tomography in Presurgical Implant Planning: A Clinical Study. J Contemp Dent Pract 2017;18(8):665-669.

Source of support: Nil

Conflict of interest: None

\section{INTRODUCTION}

Implants have emerged as new treatment modalities for partially or completely edentulous ridges. The placement of implant provides benefit to patient as it requires good 
esthetic results and no crown preparation as is done in case of fixed partial denture. Preoperative diagnosis and treatment planning are fundamental requirements to ensure success rate. Precise radiographic assessment of available alveolar bone and identification of characteristic bone morphology are of prime importance for dental implant placement. ${ }^{1}$ The distance of anatomical structures, such as mental foramen, floor of nasal cavity, floor of maxillary sinus, inferior alveolar canal, nerves, and vessels can significantly affect the morbidity of the surgical procedure and influence the outcome. ${ }^{2}$ Earlier, the implant site was assessed with the help of twodimensional (2D) imaging modality, such as intraoral periapical radiograph and panoramic radiographs. Since these imaging modalities are 2D, there are restrictions of implant planning leading to implant failures. With the advent of cone-beam computed tomography (CBCT), this limitation has been overcome. ${ }^{3}$ The CBCT provides all three dimensions (3D) and has been proved as a tool to radiology, especially in the success of implant. It provides high spatial resolution and offers less patient exposure as compared with full mouth radiographs and computer tomography. The CBCT images become essential when there is proximity of area to vital structures. Clinical method for assessing edentulous ridges transversely is ridge mapping, in which sharp-beaked calipers are used to measure the faciolingual width of the residual bony ridge at the proposed implant site. ${ }^{4}$

This study was conducted to evaluate the reliability of orthopantomography (OPG) and CBCT in presurgical implant planning.

\section{MATERIALS AND METHODS}

This study was conducted in the year 2010. It was conducted on 110 partially or completely edentulous adult patients (male 50 and female 60). Patient information regarding name, age, gender, and so forth was recorded.

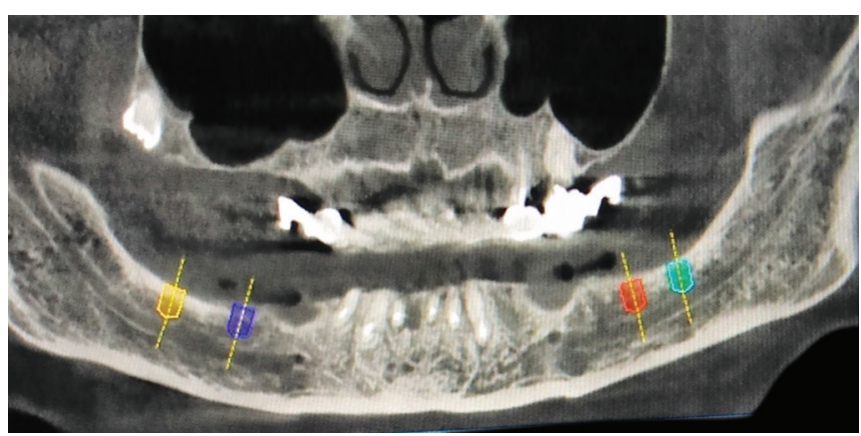

Fig. 1: Implant planning on OPG

Thorough clinical examination was done to locate the edentulous site for the placement of implant. All patients were subjected to OPG and CBCT.

The OPG was taken with digital panoramic unit (Planmeca) operating at $120 \mathrm{kVp}, 2 \mathrm{~mA}$, and exposure time of 17 seconds. The CBCT was taken using NewTom machine with field of view $11 \times 8 \mathrm{~cm}$ and resolution of $0.3 \times 0.3 \times 0.3 \mathrm{~mm}$ operating at $120 \mathrm{kVp}$ at $5 \mathrm{~mA}$. NNT software with slice thickness of $0.1 \mathrm{~mm}$ was used in this study. Measurement of bone height and distance from anatomical structures was done on OPG (Fig. 1), whereas bone height and bone width were measured on CBCT scan in all three planes, such as coronal plane, sagittal plane, and axial plane (Figs 2-5).

Since OPG is 2D, buccolingual assessment is not possible. In CBCT (3D) apart from measuring the height, diameter of implant was done in all three planes.

The measurement was done by two experienced observers. Results thus obtained were subjected to statistical analysis; $\mathrm{p}<0.05$ was considered statistically significant.

\section{RESULTS}

Table 1 shows that the present study comprised 110 patients (male 50 and female 60). Graph 1 shows that 102
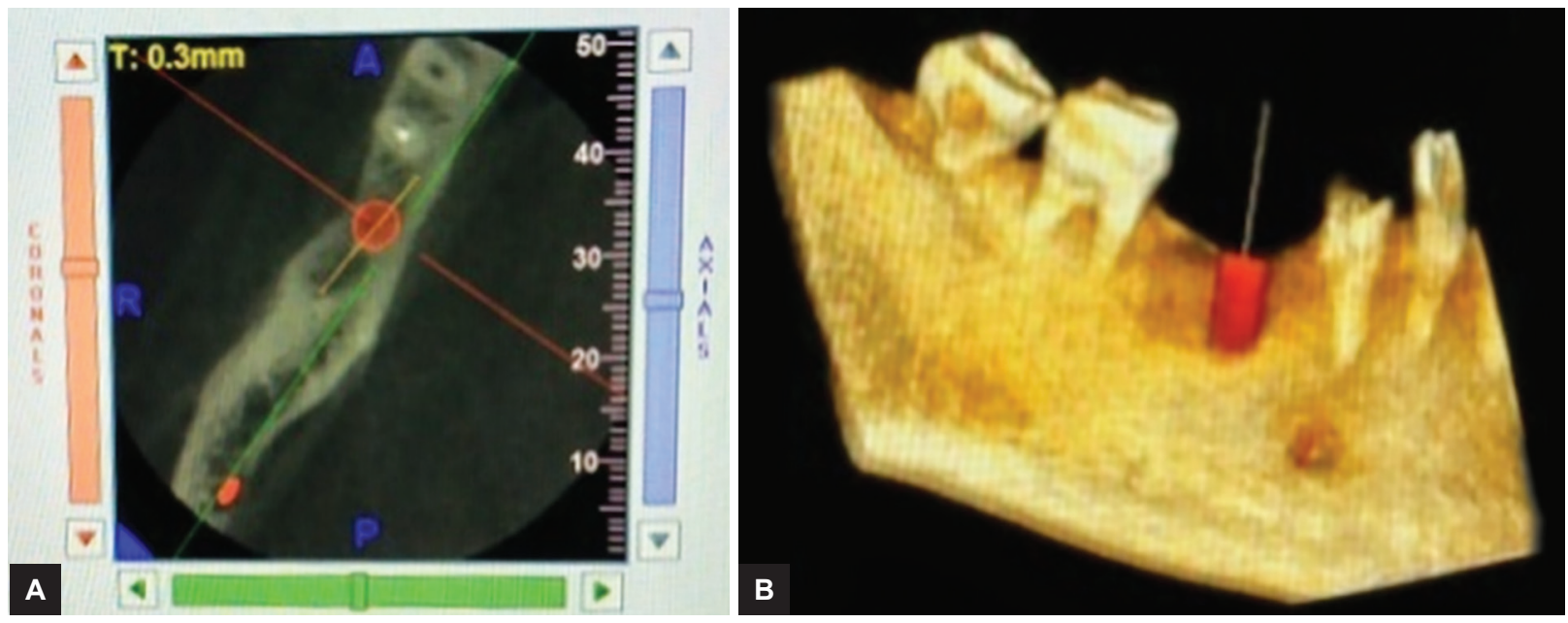

Figs 2A and B: Implant planning on $\mathrm{CBCT}$ 

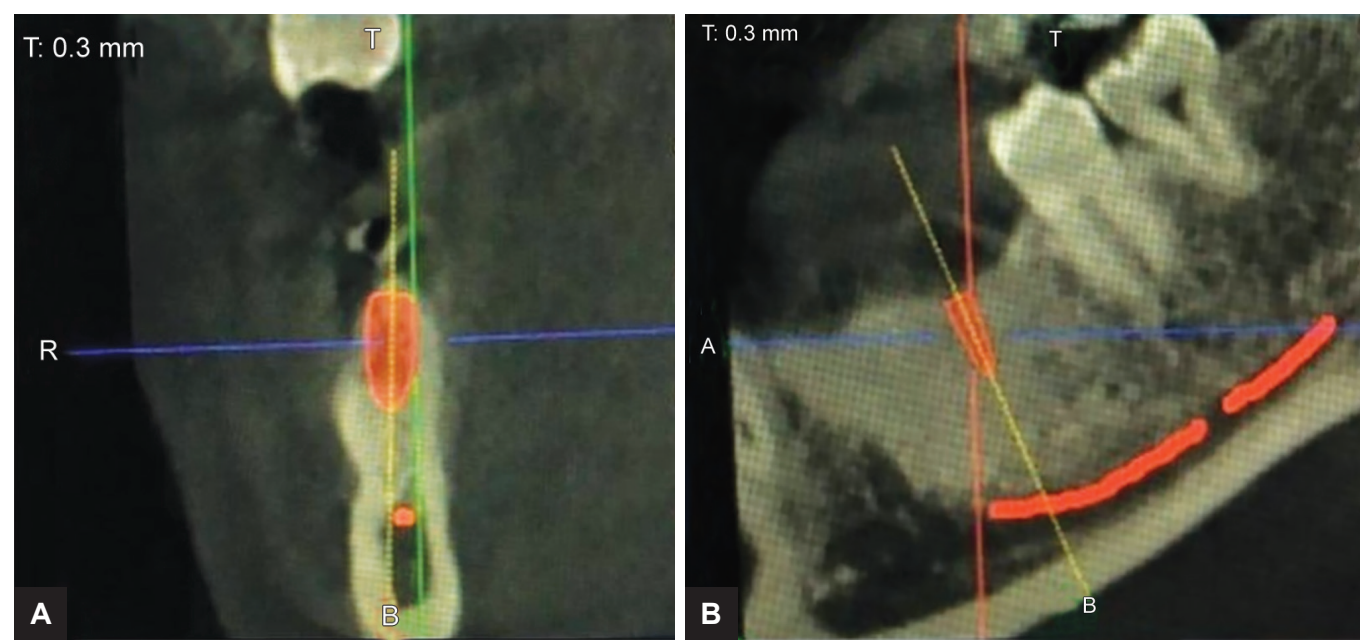

Figs 3A and B: Assessment of available bone height and width on CBCT

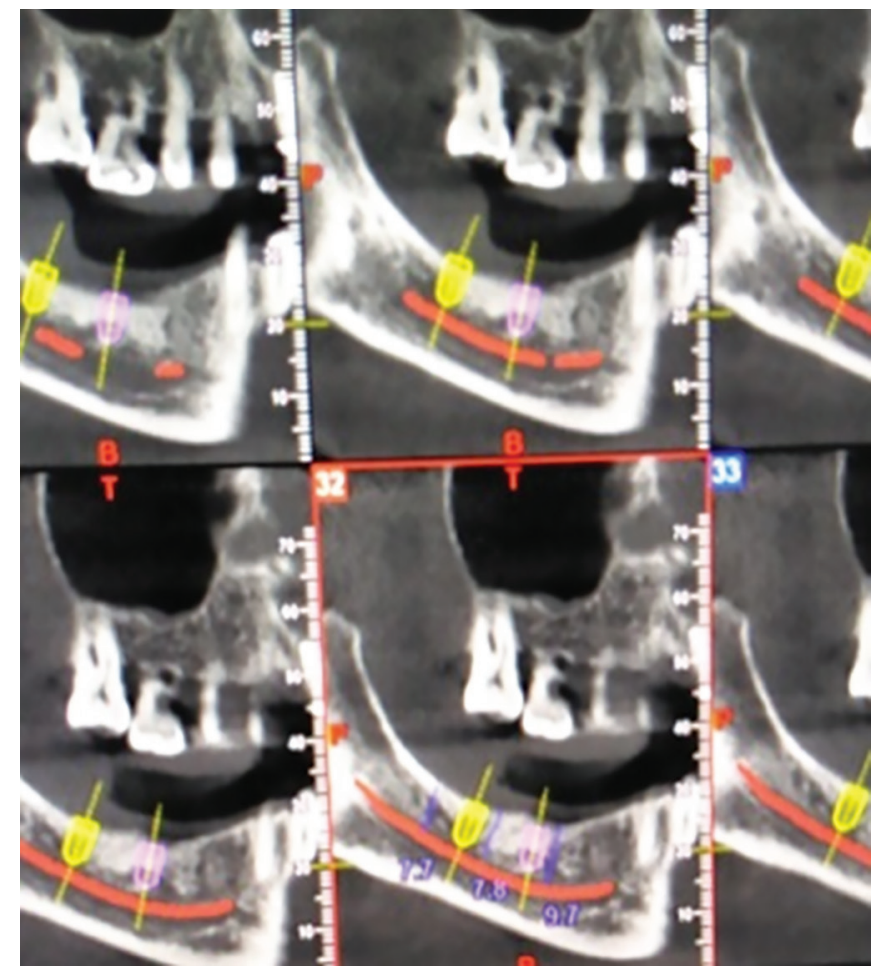

Fig. 4: Measurement of height of bone and implant

(16.7\%) implants were placed in anterior region and 508 $(83.3 \%)$ implants were placed in posterior region. Graph 2 shows that implant site was incisor region (55), canine (30), premolar (250), and molar (275). The difference was significant $(\mathrm{p}<0.01)$. Table 2 showed presurgical planning variations with CBCT and OPG. The length and width of implant remained unchanged in 90 and $85 \%$ of the cases respectively. In $8 \%$ of cases, OPG revealed more length of implant than CBCT, whereas only in $2 \%$ cases CBCT revealed more length of implant than OPG. The difference was significant $(\mathrm{p}<0.05)$. When we compared the diameter, OPG revealed more diameter mesiodistally in $10 \%$ of cases, whereas CBCT only revealed increased diameter in $5 \%$ of cases measured both from mesiodistal

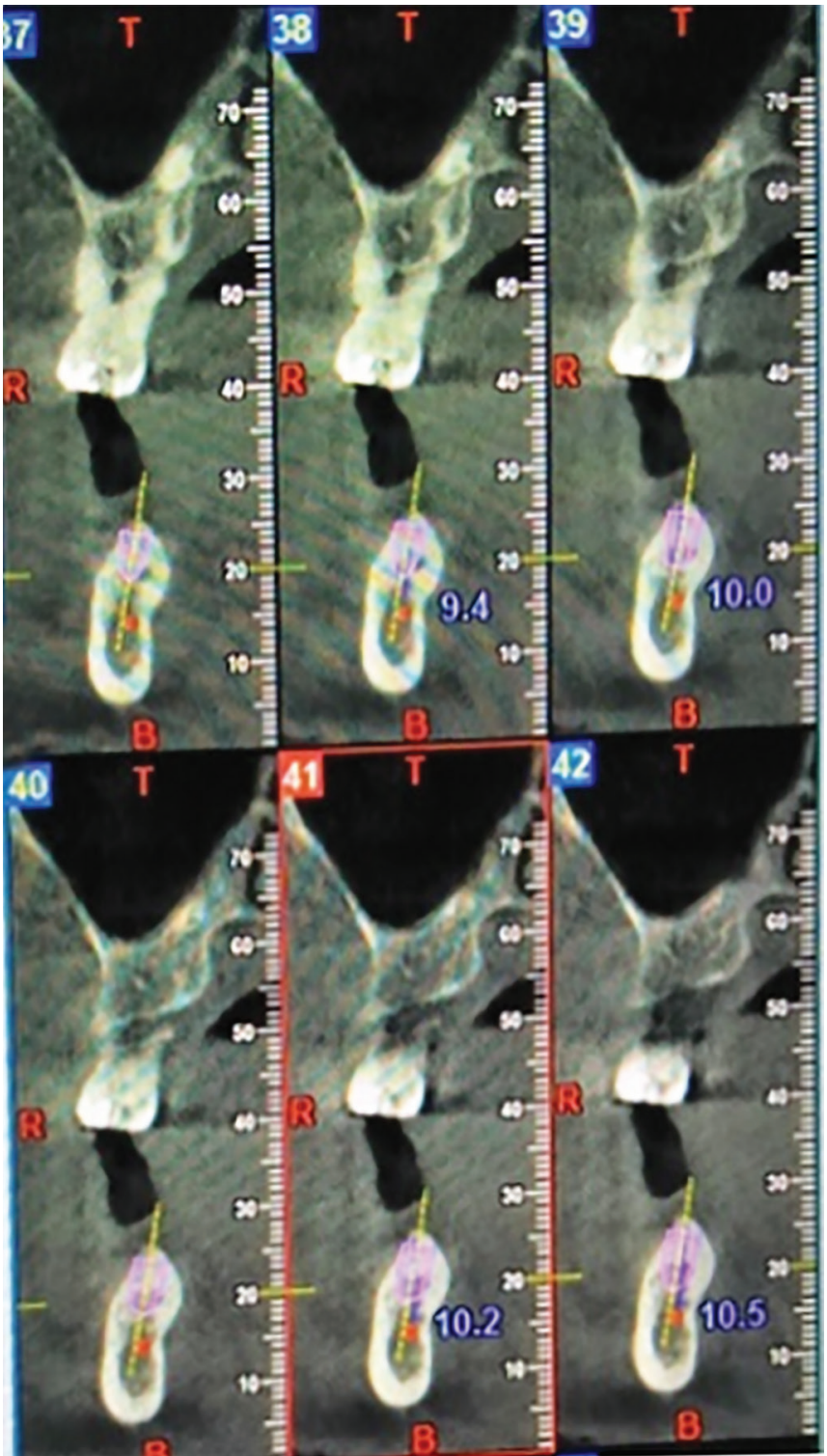

Fig. 5: Measurement of width of bone and implant

and buccolingual aspect. The difference was significant $(\mathrm{p}<0.05)$. Graph 3 shows that the observer found CBCT effective in $95 \%$ of cases and ineffective in only $5 \%$ of 
Table 1: Distribution of patients

\begin{tabular}{lll}
\hline Total - 110 patients & & \\
\hline Gender & Male & Female \\
Number & 50 & 60
\end{tabular}

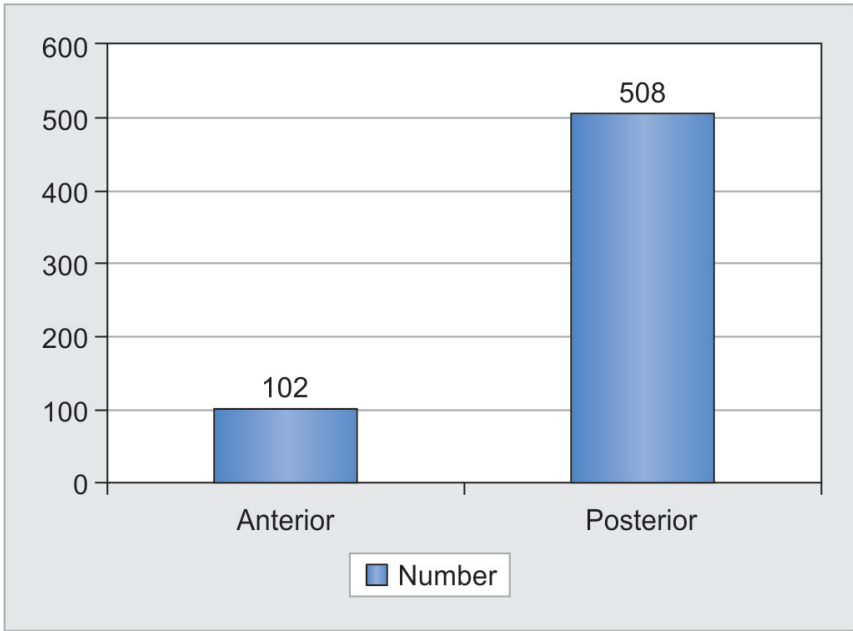

Graph 1: Distribution of implant site

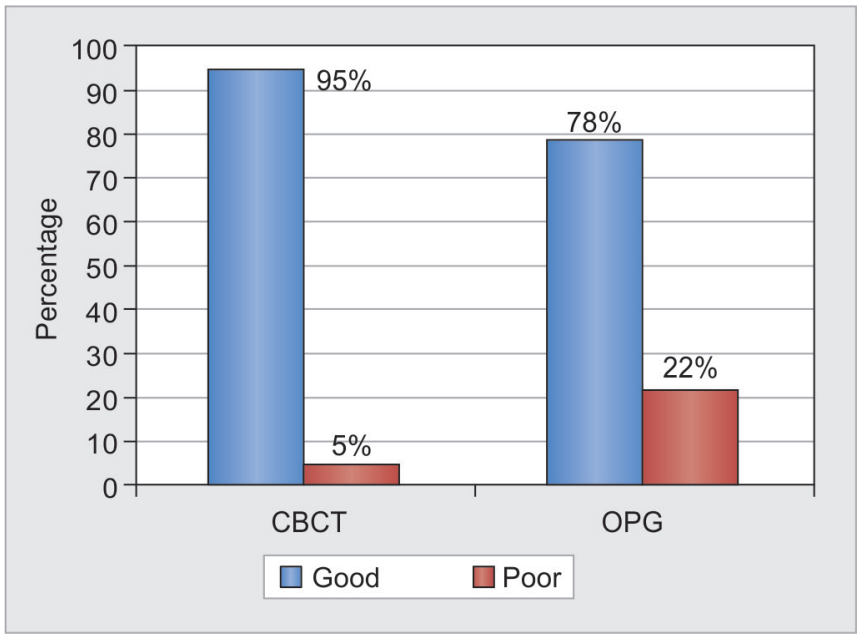

Graph 3: Image quality of OPG and CBCT as observed by observer

cases, whereas OPG was effective in $78 \%$ of cases and effective in $22 \%$ of cases. The different was significant $(\mathrm{p}<0.05)$.

\section{DISCUSSION}

With the advent of CBCT, the implant planning has become easy. Suitable treatment planning is a basic step of implant therapy for the selection of an implant with the appropriate size, dimensions, and location. With 2D imaging modality, such as OPG, one cannot evaluate the complexity of the bone volume because of superimposition of the different structures. There is limitation of assessment of bone volume and orientation with OPG. ${ }^{5}$ This study was conducted to evaluate the reliability of OPG and CBCT in presurgical implant planning.
Table 2: Variation on presurgical planning with panoramic radiography $(\mathrm{OPG})$ and $\mathrm{CBCT}(\mathrm{n}=610)$

\begin{tabular}{llll}
\hline Length of implant & Number (\%) & $\begin{array}{l}\text { Diameter of } \\
\text { implant }\end{array}$ & Number (\%) \\
\hline OPG $=$ CBCT & $549(90)$ & OPG $=$ CBCT & $519(85)$ \\
OPG $>$ CBCT & $48(8)$ & OPG $>$ CBCT & $61(10)$ \\
OPG $<$ CBCT & $13(2)$ & OPG $<$ CBCT & $30(5)$ \\
\hline
\end{tabular}

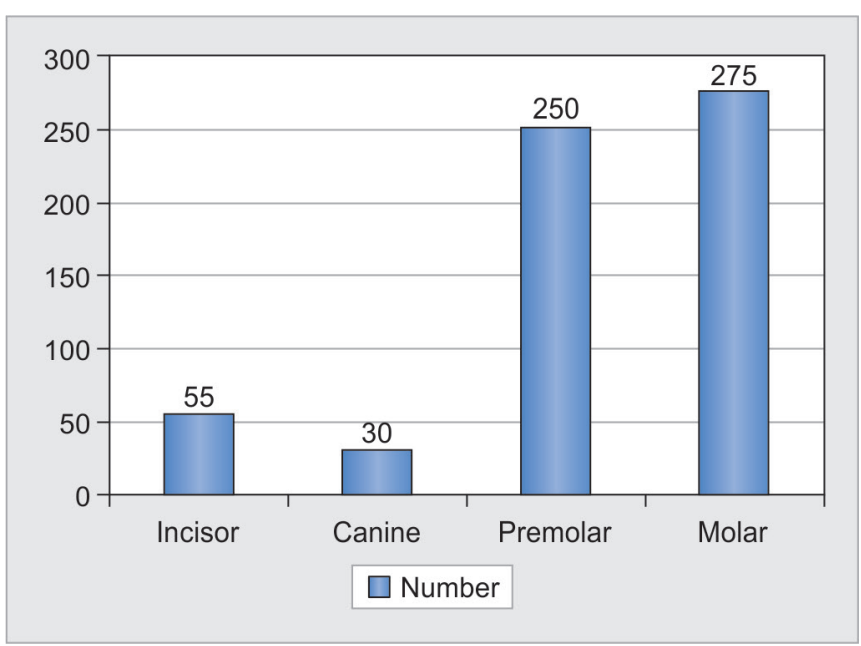

Graph 2: Position of implant

The present study comprised 110 patients (male 50 and female 60). In 16.7\%, implants were placed in anterior region and in $83.3 \%$ implants were placed in posterior region. In their study, Loubele et $\mathrm{al}^{6}$ compared OPG with $\mathrm{CBCT}$ in implant planning. Implant planning was done in $35 \%$ of anterior region and $65 \%$ of posterior region.

Implant site was incisor region (55), canine (30), premolar (250), and molar (275).

We also compared presurgical implant planning variations with CBCT and OPG. The length and width of implant remained unchanged in 90 and $85 \%$ of the cases respectively. In $8 \%$ of cases, OPG revealed more length of implant than CBCT, whereas only in $2 \%$ cases CBCT revealed more length of implant than OPG. Our results are in agreement with the results of Correa et $\mathrm{al}^{7}$ who studied implant size (width and length) planned with digital panoramic radiographs, $\mathrm{CBCT}$ in 71 patients with a total of 103 implant sites in the upper premolar and/or lower molar regions. They observed that the implant-tobe was significantly narrower and shorter when recorded in CBCT-cross than in digital panoramic radiography (D-PAN). For premolar sites, the width also differed significantly between D-PAN and CBCT-pan modalities. The implant-to-be was also significantly shorter when recorded in CBCT-cross than in D-PAN. In premolar sites, there were no significant differences in implant length among the three image modalities. ${ }^{7}$

A study conducted by Chen et $\mathrm{al}^{8}$ found that the length and width of implant remained unchanged in 60 and $75 \%$ of the cases. 
When we compared the diameter, OPG revealed more diameter in $10 \%$ of cases, whereas CBCT only revealed $5 \%$ of cases.

Baba et $\mathrm{al}^{9}$ in their study also found similar results. However, Peker et $\mathrm{al}^{10}$ in their study found that in $24 \%$ of cases OPG revealed more diameter of implant, whereas only $4 \%$ of cases CBCT showed more diameter.

Observer found CBCT as better in $95 \%$ of cases and poor in only $5 \%$ of cases, whereas OPG was better in $78 \%$ of cases and poor in $22 \%$ of cases. Kullman et $\mathrm{al}^{11}$ in their study found CBCT as good in $81 \%$ of cases in demonstrating anatomical structures more effectively.

Miles and Danforth ${ }^{12}$ showed that conventional tomography had little effect on the treatment planning of implant dimensions in posterior mandible cases. In their study, treatment plans with and without tomograms were identical in $91 \%$ implant sites. In only $9 \%$ of these cases, implant diameters had changed, while no changes occurred in the implant length after the use of tomograms.

Naitoh et al ${ }^{13}$ reported that CBCT images were significantly better than OPG with respect to the visualization and delineation of the lamina dura and the periodontal ligament space.

\section{CONCLUSION}

Successful implant placement can be ensured by taking into account the patient's prosthetic needs, functional requirements, and anatomical constraints. During the assessments, $\mathrm{CBCT}$ being $3 \mathrm{D}$ contributes to a greater success rate due to its ability to visualize previously undetectable anatomic variability and pathology. The CBCT-generated images provide detailed information that $2 \mathrm{D}$ radiographs cannot offer, which aids in precision, to further improve the entire implant process.

\section{REFERENCES}

1. Pette GA, Norkin FJ, Ganeles J, Hardigan P, Lask E, Zfaz S, Parker W. Incidental findings from a retrospective study of 318 cone beam computed tomography consultation reports. Int J Oral Maxillofac Implants 2012 May-Jun;27(3):595-603.

2. Hu KS, Choi DY, Lee WJ, Kim HJ, Jung UW, Kim S. Reliability of two different presurgical preparation methods for implant dentistry based on panoramic radiography and cone-beam computed tomography in cadavers. J Periodontal Implant Sci 2012 Apr;42(2):39-44.

3. Perez LA, Brooks SL, Wang HL, Eber RM. Comparison of linear tomography and direct ridge mapping for the determination of edentulous ridge dimensions in human cadavers. Oral Surg Oral Med Oral Pathol Oral Radiol Endod 2005 Jun;99(6):748-754.

4. Allen F, Smith DG. An assessment of the accuracy of ridgemapping in planning implant therapy for the anterior maxilla. Clin Oral Implants Res 2000 Feb;11(1):34-38.

5. Tepper G, Hofschneider UB, Gahleitner A, Ulm C. Computed tomographic diagnosis and localization of bone canals in the mandibular interforaminal region for prevention of bleeding complications during implant surgery. Int J Oral Maxillofac Implants 2001 Jan-Feb;16(1):68-72.

6. LoubeleM,Guerrero ME,Jacobs R, Suetens P, vanSteenbergheD. A comparison of jaw dimensional and quality assessments of bone characteristics with cone-beam CT, spiral tomography, and multi-slice spiral CT. Int J Oral Maxillofac Implants 2007 May-Jun;22(3):446-454.

7. Correa LR, Spin-Neto R, Stavropoulos A, Schropp L, da Silveira HE, Wenzel A. Planning of dental implant size with digital panoramic radiographs, CBCT-generated panoramic images, and CBCT cross-sectional images. Clin Oral Implants Res 2014 Jun;25(6):690-695.

8. Chen LC, Lundgren T, Hallström H, Cherel F. Comparison of different methods of assessing alveolar ridge dimensions prior to dental implant placement. J Periodontol 2008 Mar;79(3):401-405.

9. Baba R, Ueda K, Okabe M. Using a flat-panel detector in high resolution cone beam CT for dental imaging. Dentomaxillofac Radiol 2004 Sep;33(5):285-290.

10. Peker I, Alkurt MT, Michcioglu T. The use of 3 different imaging methods for the localization of the mandibular canal in dental implant planning. Int J Oral Maxillofac Implants 2008 May-Jun;23(3):463-470.

11. Kullman L, Al-Asfour A, Zetterqvist L, Andersson L. Comparison of radiographic bone height assessments in panoramic and intraoral radiographs of implant patients. Int J Oral Maxillofac Implants 2007 Jan/Feb;22(1):96-100.

12. Miles DA, Danforth RA. Cone beam computed tomography: from capture to reporting. Dent Clin North Am 2014 Jul;58(3):463-716.

13. Naitoh M, Kawamata A, Iida H, Ariji E. Cross-sectional imaging of the jaws for dental implant treatment: accuracy of linear tomography using a panoramic machine in comparison with reformatted computed tomography. Int J Oral Maxillofac Implants 2002 Jan-Feb;17(1):107-112. 